\title{
Functional consequences of the transcallosal removal of intraventricular tumours
}

\author{
M. A. JE E VES, D. A. S I M PSON, A N D G. GE F FE N \\ From the Psychological Laboratory, University of St Andrews, Scotland, the Department of \\ Neurosurgery, Adelaide Children's Hospital, and Psychology Discipline, The Flinders University \\ of South Australia, Adelaide, South Australia
}

S U M MARY Colloid cysts and other benign tumours of the third and lateral ventricles may be exposed through a small incision in the body of the corpus callosum. This approach is practicable even when ventricular dilatation is slight, and is theoretically less likely to cause epilepsy than the more usual transcortical approach. Disturbances of memory have been noted soon after such operations, but do not cause serious long-term disability. Three patients who underwent transcallosal removal of cysts or tumours some years earlier have been tested by procedures designed to demonstrate interhemispheric transfer of information: they were all found to have defects in transfer of tactile data, but not of information obtained visually. They were not aware of this inability, and do not appear to be inconvenienced by it. The transcallosal route is convenient. The operation sacrifices a functionally significant part of the corpus callosum, but the neurological sequelae have seemed acceptable. However, especially in the elderly, stereoventriculoscopic aspiration may be considered as the initial method of treatment.

McKissock (1951) recommended that colloid cysts of the third ventricle should be exposed by a frontal transcortical approach, through an aperture made by excising a conical block of cerebral tissue. Similar transcortical operations have been used to remove tumours in the lateral ventricles. If the ventricles are dilated, the access is certainly excellent. Many surgeons consider that these transcortical operations inflict no significant disability if performed on the nondominant hemisphere.

However, the transection of frontal white matter must have some adverse consequences, even if these are not obvious. Moreover, some patients so treated later develop epilepsy; the incidence in published series (McKissock, 1965) is not high, but in occasional cases the seizures have been very disabling, and personal experience suggests that this is especially so when the operation is performed on an infant or young child.

Greenwood (1949) employed a transcallosal approach to remove two colloid cysts of the third ventricle, and advocated this method in preference

Address for reprint requests: Professor M. A. Jeeves, Psychological Laboratory, University of St Andrews, Fife KY16 9AL.

Accepted 7 September 1978 to the transcortical route. More recently, Long and Chou (1973) have used this route to remove craniopharyngiomas in the third ventricle, without, however, reporting on its long-term neurological complications. Such an approach may, on theoretical grounds, be expected to minimise the likelihood of postoperative epilepsy. However, recent studies of the behavioural disabilities experienced by patients subjected to complete midline commissurotomy have shown the importance of the great commissures in the transfer of information from one hemisphere to another (Gazzaniga, 1970; Sperry, 1970), and also in short-term retention of information (Zaidel and Sperry, 1974; Dimond et $a l .$, 1977). If transcallosal surgery is to be recommended, it is important to establish the safety of the procedure in terms of long-term functional capacities. We report the cases of three patients who underwent transcallosal removal of colloid cysts (two cases) or intraventricular astrocytomas (one case, two tumours). These patients have been reviewed some years after the operations, and investigated by a battery of tests devised to demonstrate interhemispheric transfer and, in one patient, memory abilities. 


\section{Case reports}

\section{CASE 1}

A girl aged 14 years (WF) had complained of headache over the last two months, with increasing lethargy. On the day of her admission, she passed into a state of rapidly deepening coma. While in hospital, she ceased to breathe and her pupils became fixed. Ventricular drainage was instituted, and ventriculography with air and sodium iophendylate was performed. This investigation demonstrated what appeared to be a midline tumour in the septum pellucidum.

An attempt was made to perform a ventriculocisternal shunt, but in the course of this, the "tumour" was tapped, and a certain amount of dark fluid containing cholesterol was obtained.

After these investigations, she exhibited a left facial and brachial hemiparesis with some dyskinesia. There was marked impairment of recent memory and she was apathetic, confused, and incontinent.

At operation (15 October 1971), the right frontal lobe was exposed through a small craniotomy. The frontal lobe was retracted after division of one large vein. This permitted exposure of the corpus callosum; the pericallosal arteries were retracted to the left and the body of the corpus callosum was incised, posterior to the genu which was preserved. The length of the incision was probably less than $30 \mathrm{~mm}$. When this was done, the lateral ventricle could be explored, and a greyish-green cyst was seen occupying the foramen of Monro. It contained yellow fluid, and also a certain amount of necrotic material. To expose it fully, it was necessary to divide the pillars of the fornix, and when this was done it was possible to strip the tumour away from the tela choroidea.

This operation was well tolerated. The left facial and brachial paresis rapidly recovered, as did a postoperative complaint of abnormal thirst, but for some time there was a marked impairment of recent memory. Histologically, the cyst was originally considered to be an epidermoid, but further examination led to reclassification as a colloid (so-called paraphyseal) cyst.

After discharge, there was further clinical improvement, and the girl was able to complete a normal education. Five years after the operation she is very well and has no neurological symptoms except forgetfulness over minor matters; she finds a diary helpful. She is attending a teacher's training college and is expected to qualify as a primary school teacher.

\section{CASE 2}

This man (GO), aged 64 years, complained of episodes of depression, impaired mental concentration, and sudden attacks of weakness in the legs which caused falling without warning. Examination showed him to be oriented in time and place, but with a significant defect in recent memory. There was symmetrical tendon hyperreflexia but plantar responses were flexor. The optic fundi were normal.

Carotid angiography showed evidence of hydro-

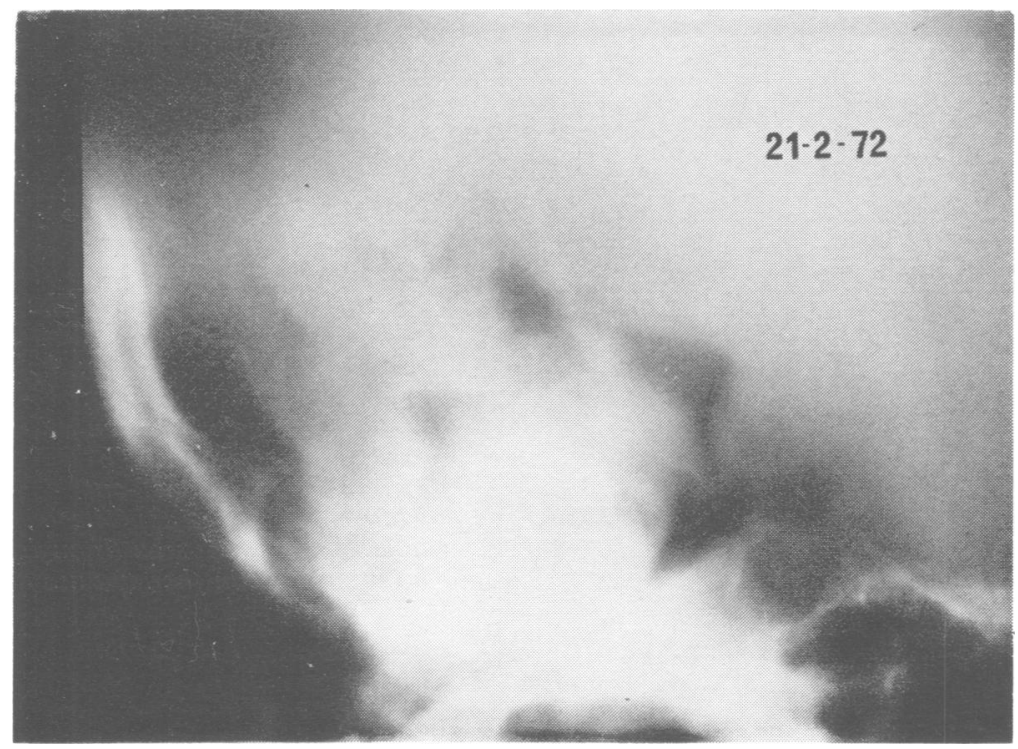

Fig. 1 Case 2. Lumbar pneumoencephalogram. A lateral tomogram obtained during air injection shows a globular mass occupying the anterior part of the third ventricle and obstructing the foramina of Monro. 
cephalus, and a lumbar pneumoencephalogram showed a mass $20 \mathrm{~mm}$ in diameter occupying the anterior third ventricle. Filling of the lateral ventricles was incomplete (Fig. 1).

A colloid cyst of the third ventricle was diagnosed. At operation on 10 March 1972 the right frontal lobe was exposed through a small bone flap. It was retracted from the falx and, after the sacrifice of one small bridging vein, the corpus callosum was exposed in a distance of about $30 \mathrm{~mm}$ (Fig. 2). After separation of the two anterior cerebral arteries, the corpus callosum was incised, and the dilated lateral ventricle was opened. A cyst could be seen occupying the foramen of Monro on the right side, with a large vein-presumably the septal vein-running over its surface. It was necessary to incise white matter (probably thinned-out fornix) to expose the posterior surface of the cyst, which was tough and rubbery; it contained semi-solid material and, when this was evacuated, the cyst collapsed and could easily be detached from its vascular adhesions. Removal was complete, with no damage to neurological structures other than the corpus callosum itself and a portion of the right fornix.

This operation was well tolerated, and the patient showed no obvious ill effects during his convalescence. His subsequent course has, however, been less satisfactory. Some 18 months after this operation, he was readmitted in a depressed state, with evidence of impaired recent memory. Further lumbar pneumoencephalography was performed, demonstrating considerable ventricular dilatation, and a CSF isotope transport study suggested delay in CSF absorption externally. A ven- triculoatrial shunt was performed, and this, together with appropriate psychiatric treatment, somewhat improved his condition. Five years after the original operation, depression no longer appears to be a significant problem, but he remains diffident, reticent, and very much dependent on his wife. He now denies any memory defect, and his wife endorses this. He accurately recalled an address and the name of a flower after an interval of five minutes when last seen.

CASE 3

This patient (SF) was investigated at the age of 7 months because of enlargement of his head; a pneumoencephalogram was performed, but no significant abnormality was found. He suffered two convulsions, associated with febrile illnesses, during the first year of life, but thereafter his parents considered that he developed normally.

At the age of five years, he began to complain of headache, and was found to have severe bilateral papilloedema. It was noted that he had numerous areas of absence of normal skin pigmentation, suggesting the diagnosis of tuberose sclerosis (epiloia). $\mathrm{He}$ also had haemangiomatous thickening of two fingers of his left hand.

Plain skull radiographs showed several areas of abnormal intracranial calcification, and also wellmarked sutural diastasis. A nuclide brain scan showed abnormal uptake in the left hemisphere. Carotid angiography and ventriculography showed slight hydrocephalus, with evidence of two glo-e bular intraventricular masses, the larger of which? was in the left lateral ventricle. It did not appear, however, to be obstructing the ventricle.

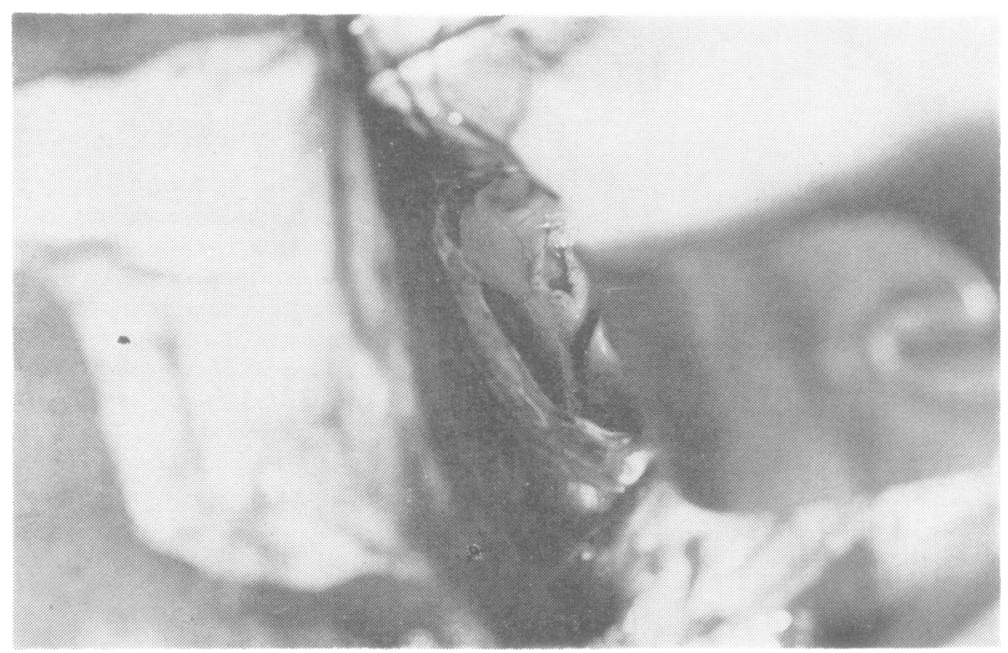

Fig. 2 Access to the right lateral ventricle through the corpus callosum in case 2. The pericallosal arteries are visible to the left of the exposure; the cyst is largely concealed, but its posterior pole has been exposed through a small incision in the thinned-out white matter. The opposite lateral ventricle is seen through a fenestration in the septum. 
A spinoperitoneal shunt was performed, in order to relieve the child's papilloedema. This improved, but the child remained very unwell, and developed a right sided hemiparesis.

At operation (23 May 1974), a left frontal craniotomy was performed. The corpus callosum was exposed by retraction laterally of the left frontal lobe; it was necessary to sacrifice one of the precentral veins. The corpus callosum was transected in the midline, with preservation of the pericallosal arteries; a grey, fleshy intraventricular tumour was found, and this was removed completely. It was adherent on its ventral surface to the floor of the lateral ventricle, probably in the region of the caudate nucleus; lateral to the tumour, there was a large cyst containing yellow fluid. No attempt was made to remove the smaller mass in the right lateral ventricle, as it was assumed to be a non-neoplastic tuber. The tumour was a typical benign giant-celled astrocytoma (Russell and Rubinstein, 1977).

This operation was well tolerated. There was a dramatic improvement in the child's hemiparesis, and he remained very well for the next 16 months.

He was readmitted on 18 September 1975, complaining of a recurrence of severe headache; examination showed slight bilateral papilloedema and a mild residual weakness of the right leg. A nuclide brain scan showed increased uptake, this time to the right of the midline, and a pneumoencephalogram demonstrated a mass in the right lateral ventricle.

A second transcallosal exploration was performed on 23 September; this time, the corpus callosum was approached by a right frontal craniotomy and sectioned posterior to the genu but anterior to the previous exploration. The tumour was found in the region of the foramen of Monro, which presumably had been intermittently blocked, and was removed, apparently completely. It was, like the first tumour, a giant-celled astrocytoma.

These two callosal sections evidently involved the whole of the body of the corpus callosum, with preservation of the genu and the rostrum. Posteriorly, the section certainly did not reach the splenium, which was not visualised.

After this second operation, the child remained reasonably well, though handicapped by frequent minor epileptic seizures. He resumed school, though his attendance was intermittent, partly because of his seizures and partly because of a significant intellectual handicap.

When reviewed on 20 April 1977 he seemed a happy and co-operative child, without any obvious speech defect. He had a mild hemiparesis, chiefly affecting the facial muscles, but this did not constitute a serious disability. It is considered that his intellectual retardation represents the effects of generalised tuberose sclerosis as well as the damage inflicted by his two intraventricular astrocytomas.

\section{Surgical technique}

These four transcallosal operations, and two others done to explore what proved to be inoperable malignant gliomas, have presented no special diffculties. The retraction of the frontal lobe (Fig. 2) has entailed sacrifice of one draining vein only. The body of the corpus callosum has been easily identified under magnification, and the pericallosal arteries have been either separated or retracted after microsurgical dissection. In case 3, one callosomarginal branch on each side had to be sacrificed, without evident ill effects. Section of the corpus callosum is begun with a fine knife and completed with the sucker tip. With the aid of the operating microscope, a section about $30 \mathrm{~mm}$ long has been sufficient even for the comparatively large intraventricular astrocytomas found in case 3 (Fig. 3).



Fig. 3 Diagram showing (shaded) the portion of the corpus callosum divided in cases 1 and 2 ; in case 3 , the section extended further in the caudal direction, but did not involve the splenium.

The two colloid cysts were removed in toto, after aspiration of their contents. This was done in case 1 because the cyst was misdiagnosed on frozen section as a craniopharyngioma. Both fornices had to be sacrificed and, had the true nature of the cyst been known, a more conservative procedure relying on coagulation of the cyst capsule might have been proper. In case 2 , total removal was undertaken simply because it seemed, and was, easy to do so; a part only of one thinned-out fornix was sacrificed. 
In all three cases, the exposure of the ipsilateral frontal horn, foramen magnum, and body of the lateral ventricle was most satisfactory. In case 2 , the anterior part of the opposite lateral ventricle could be explored through a pre-existing fenestration in the septum lucidum; in case 1 , such a fenestration had to be made. It has never yet been necessary to abandon a projected transcallosal exploration and to have to resort to a transcortical procedure. This change in approach would be easy, and might be necessary if the anatomy of the draining veins or the pericallosal vessels was unfavourable, or if there were dense interhemispheric adhesions.

As Long and Chou (1973) point out, the transcallosal exposure, unlike the transcortical approach, can be recommended even when there is little ventricular dilatation. In one of our cases (GO) there was considerable ventricular dilatation; in the other two, and in the fourth case not reported here, the ventricular dilatation was not great.

\section{Neurological and psychological sequelae}

Superficially, it can be said that these three cases recovered quite well. The first patient (WF) completed a secondary school education, matriculated, and now copes well with tertiary education in a teachers' college. Her early defect in recent memory is now scarcely evident to her or to observers. The second patient's status is less satisfactory; however, he is 69 years old, and some of his depression and occasional irritability may express his age. The third patient is certainly retarded, but his coexisting tuberose sclerosis may well explain this.

To explore the effects of these restricted callosal sections, all three patients were tested by two of us (MAJ and GG), by methods aimed particularly at analysing specialisation of function within the corpus callosum in the interhemispheric transfer of information (Gazzaniga, 1970; Jeeves, 1978), and the selective role it may play in memory (Zaidel and Sperry, 1974). Two patients (cases 1 and 3) were tested in a psychological laboratory, and one patient (case 2) in a hospital outpatient clinic. In cases 1 and 2, the tests were performed five years after the callosal sections; in case 3 , the second section had been performed some 18 months earlier. The testing procedures and results obtained are described below. A summary of the results is presented in Table 1 .

TOUCH LOCALISATION

Using a variant of the technique developed by
Table 1 Summary of results of psychological testing

\begin{tabular}{|c|c|c|}
\hline Task & $\begin{array}{l}\text { Number of } \\
\text { patients } \\
\text { tested }\end{array}$ & Result \\
\hline Touch localisation & 3 & $\begin{array}{l}\text { Deficit on cross-lateralisation } \\
\text { No deficit on ipsilateral } \\
\text { testing }\end{array}$ \\
\hline $\begin{array}{l}\text { Bimanual co-ordination } \\
\text { (Bead stringing) }\end{array}$ & 3 & Deficit \\
\hline $\begin{array}{l}\text { Transfer of tactile } \\
\text { learning (Formboard) }\end{array}$ & 1 & Deficit-no transfer \\
\hline $\begin{array}{l}\text { Transfer of pencil } \\
\text { maze learning }\end{array}$ & 2 & Deficit in one patient \\
\hline $\begin{array}{l}\text { Naming by touch of } \\
\text { familiar objects }\end{array}$ & 3 & No deficit \\
\hline $\begin{array}{l}\text { Naming by touch of } \\
\text { digits }\end{array}$ & 3 & No deficit \\
\hline Chimeric faces & 2 & $\begin{array}{l}\text { No deficit-nature of stimuli } \\
\text { seen at once. One patient } \\
\text { showed asymmetry of } \\
\text { pointing favouring right } \\
\text { visual field }\end{array}$ \\
\hline $\begin{array}{l}\text { General intellectual } \\
\text { level and memory }\end{array}$ & 1 & $\begin{array}{l}\text { Deficit-attenuated picture } \\
\text { of deficit found in total } \\
\text { commissurotomies }\end{array}$ \\
\hline
\end{tabular}

Kinsbourne and Warrington (1962) (Dennis, 1976), the subject's hands were placed under a screen, palms upwards. It was explained that the tip of one finger would be lightly touched; the subject $\overline{1}$ was asked to indicate which finger was touched by touching the finger with the thumb of the same hand. Next, in the contralateral testing condition, the subject was asked to indicate in the same ways but on the opposite, non-stimulated hand. Withince each batch of trials, each finger was touched five? times in a pseudo-random order.

On ipsilateral testing, all three patients performed as normal subjects. All three showed deficits on cross-lateralisation. In cases 1 and 2 (WF and GO), the deficit was more marked when the left hand was touched and the right hand had to respond; in case 3 (SF), the deficit was greater when the right hand was touched. Retesting improved the scores in the two patients (cases 1 and 3) who were able to return for further examination. It appeared that this improvement was the result of implicit verbal identification (case 1) or ipsilateral self-stimulation providing bilaterally represented movement cues (case 3 ) of the previously stimulated finger. Such strategies presumably use alternative and intact intra- or interhemispheric pathways and have been reported in total commissurotomy patients (Gazzaniga, 1970).

\section{BEAD STRINGING}

This simple task, which has been used to study bimanual co-ordination in acallosals (Jeeves, 1965; Reynolds and Jeeves, 1977) requires the subject to 
thread as many beads as possible on a lace in two minutes. All three patients performed considerably below the level of matched control subjects.

THREE-HOLE FORMBOARD

The subject is given the pieces-a circle, a triangle, and a square. He slides his hand under a curtain which prevents him from seeing the board, and feels the holes; then, at the word "Go," he fits the pieces into the board as fast as he can. After five trials, the untrained hand is tested for transfer of this new skill. Only case 2 was so tested, and no evidence of transfer was found.

\section{PENCIL MAZE}

A metal 10 choice point maze (Corkin (1965), Lafayette Instrument $\mathrm{Co}$ ) is placed behind the screen. The subject's hand is guided to the start hole and to the finish hole, and the extremities of the maze are felt. He is asked to go from start to finish as quickly as he can, and the time for each trial is recorded. If he can, he is encouraged to complete 20 timed trials with the preferred hand, and then to perform several timed trials with the non-preferred hand.

Case 1 showed clear evidence of transfer of learning after 15 trials; case 2 showed no evidence of such transfer after six trials; case 3 was not tested. The transfer shown by case 1 could result from ipsilateral input from proximal musculature or from the patient developing and using a verbal coding of the maze pattern or both.

\section{NAMING FAMILIAR OBJECTS AND DIGITS BY TOUCH} ALONE

All three patients performed normally with both hands when asked to name by touch a set of familiar objects and a set of nine 2 ins $\times 1 \frac{1}{2}$ ins digits.

\section{CHIMERIC FACES}

When a point on the vertical meridian is fixated, the right half of the visual field projects to the left hemisphere and vice versa. Levy et al. (1972) constructed sets of chimeric figures, some were two different half faces joined at the vertical meridian, others were line drawings resembling antlers, and yet others were chainlike drawings. They reported that patients who had undergone total commissurotomy experienced no strangeness, discrepancy, or incompleteness in the evoked perceptual image. In tests of facial recognition each hemisphere apparently filled in its own half-face separately, and tended to complete the perception by filling in the unseen half of the same face in conformity with other studies of perceptual com- pletion. In right handed subjects, the right, minor hemisphere dominated the response of simple manual pointing when no language was involved. When a naming response was required to the chimeric faces the left hemisphere became dominant.

The chimeric faces were presented for periods of less than $150 \mathrm{~ms}$. After each presentation the subject inspected a set of normal photographs of whole non-chimeric faces spread on a table before him and pointed to the face he had just seen. A set of 36 colour slides of faces was presented; 12 were of normal whole faces and 24 were chimeric faces. The series was presented twice through, each time being in a pseudo-random order. On the first series, the patient responded by pointing with the right hand and, on the second series, by pointing with the left hand. After the total viewing the subject was asked if he had noticed anything unusual about any of the slides. Time did not permit the naming condition to be given since it involves learning the names to be attached to a set of faces.

Cases 1 and 3 of the present series detected the chimeric nature of the faces at once, as do normal subjects. Case 3 (SF) pointed correctly to the whole faces from which each of the two half faces were taken. He showed no asymmetry in his pointing behaviour. Case 1 (WF) said that she chose to point to the face she felt "was the dominant half." She pointed correctly to four of the half faces in her left visual field and to 11 in the right visual field and made errors on the remaining nine presentations. This asymmetry in her pointing is opposite to the results reported by Levy et al. (1972) with the total commissurotomy patients. Case 2 (GO) was not tested.

TESTS OF GENERAL INTELLECTUAL LEVEL AND MEMORY

A selection of the tests used by Zaidel and Sperry (1974) was administered to one of the patients (case 1). Those administered were the Wechsler Adult Intelligence Scale (WAIS), the Wechsler Memory Scale (WMS), Administration A of the Benton Visual Retention Test (VRT), Repeated Sequences of Above Span spoken digits and Corsi's Spatial Memory Span Test (Milner, 1971). The results on these tests are summarised in Table 2.

The rationale was that the functioning on the tests of short-term memory should be at a similar level to that on the test of intelligence, as is the case in people without brain damage.

The patient achieved a WAIS Full Scale IQ of 113, made up of a Verbal IQ of 131 and a Performance IQ of 87 . The striking discrepancy between verbal and performance IQs is very rare in 
Table 2 Tests of general intellectual ability and of memory for case 1

\begin{tabular}{|c|c|c|}
\hline Test administered & Results & Comments \\
\hline WAIS IQ & $\begin{array}{l}\text { Full scale } 113 \\
\text { Verbal } 131 \\
\text { Performance } 87\end{array}$ & $\begin{array}{l}\text { Normal } \\
\text { Above normal } \\
\text { Below normal } \\
\text { Block design and object } \\
\text { assembly performed very } \\
\text { poorly }\end{array}$ \\
\hline $\begin{array}{l}\text { Wechsler memory } \\
\text { scale }\end{array}$ & Memory quotient 80 & $\begin{array}{l}\text { Below normal in terms of } \\
\text { own IQ and age norms }\end{array}$ \\
\hline $\begin{array}{l}\text { Visual retention } \\
\text { test }\end{array}$ & Correct 12 Errors 12 & $\begin{array}{l}\text { More errors than normal } \\
\text { for own IQ and age norms }\end{array}$ \\
\hline $\begin{array}{l}\text { Spatial memory } \\
\text { span }\end{array}$ & Score of 5 & $\begin{array}{l}\text { Normal but cumulative } \\
\text { learning not evident }\end{array}$ \\
\hline Digit span & Score of 8 & $\begin{array}{l}\text { Normal but cumulative } \\
\text { learning not evident }\end{array}$ \\
\hline
\end{tabular}

the normal population. The performance deficit may be the result of local damage to the right hemisphere caused by the cyst or its removal. It is noteworthy that the WAIS subtests involving visuospatial abilities such as Block Design and Object Assembly were performed very poorly.

Overall, WF's performance on the memory tests produced an attenuated picture of that reported by Zaidel and Sperry (1974) on their total commissurotomy patients. Thus, on five out of seven WMS subtests, WF performed better than Zaidel and Sperry's patients and, indeed, on three of them her performance was as good as or superior to that of normal subjects. The story passages and associate learning were very poorly performed, scoring 5 and 6 respectively. These two subjects produced the low overall MQ of 80 . On the VRT, her score was higher than nine out of 10 of Zaidel and Sperry's patients. Her score on form C given first was poor, four correct designs and nine errors; however, on form D she obtained eight correct designs and made three errors, an expected average IQ score.

The recurrent sequences of digits showed a $10 \%$ improvement over non-current sequences, whereas the recurrent spatial sequences showed no improvement. Normal subjects show a 30-50\% improvement in both the spatial and verbal tasks (Milner, 1971). Such deficits as there are, are no serious impediment to WF, since having successfully completed the first two years, she is now in the third year of her teacher's training course.

\section{Discussion}

Our small experience of four operations performed in three patients suggests that the transcallosal approach gives satisfactory access to colloid cysts of the third ventricle and to benign tumours in the anterior parts of the lateral ventricles. The immediate effects of the operation have not been disconcerting: postoperative complaints have been few, although two patients did suffer impaired short-term memory. This favourable experience agrees with the reports of Gordon et al. (1971) on the absence of the so-called deconnexion syndrome after commissurotomies which were more extensive than ours, since they involved the genu and anterior $50 \mathrm{~mm}$ of the corpus callosum, and also the anterior commissure.

We believe that these findings support our preference for transcallosal exposure of anteriorly placed intraventricular tumours. Previous experience (of DAS) with the use of the transcortical route has been attended by a high incidence of troublesome epilepsy, especially in children. Stereotactic surgery may be still more benign (Bosch et al., 1977). One of us (DAS) has treated a colloid cyst of the third ventricle by stereotactic aspiration; the patient remains symptom-free after 10 years, though the amount of fluid aspirated was very small. A similar method of treatment, combined with visualisation by the fibre-optic ventriculoscope (Iizuka, 1971), has been used for a cystic craniopharyngioma and a suprasellar arachnoid cyst. Stereoventriculoscopic surgery of intra- $\frac{\Omega}{\circ}$ ventricular cysts has nevertheless obvious limitations, at least with present technology. The cyst contents may be too viscid for aspiration; aspiration may cause bleeding, obscuring vision or even leading to serious intraventricular haemorrhage; the cyst may recur. Bosch et al. (1977)? believe that with serial examinations by computerised tomography, it should be possible to anticipate and treat a recurrence, and in many cases, this is no doubt true. However, colloid cysts are treacherous lesions, and with many rural patients in Australia, there are often difficulties in arranging lifelong monitoring of an aspirated tumour. It is our present belief that open operation is in most cases the method of choice, though in elderly patients a preliminary stereoventriculoscopic examination may be warranted. If open operation is to be done, we consider that the transcallosal route offers good access together with an acceptably small functional disability. Whenever possible, the columns of the fornix should be preserved; Hirsch (personal communication, 1978) has reported that, in at least some cases, third ventricle tumours can be delivered by enlarging the foramen of Monro posteriorly. This entails division of the thalamostriate vein, but apparently this can be done without ill effect.

The results of two recent studies of patients with partial commissurotomies (Dimond et al., 
1977; Risse et al., 1978) complement the picture emerging from our own studies. Dimond et al. (1977) reported severe disturbances of somatic and visuospatial transfer, aphasia, and a memory disorder, in a case whose corpus callosum was divided for a distance of $25-30 \mathrm{~mm}$ in length and $10 \mathrm{~mm}$ in width. From the details given, it would appear that the sectioning extended more posteriorly than in our patients. There was additionally some operative injury to the left posterior frontal gyrus. As with our patients, their patient showed no intellectual impairment on the WAIS and no deficit on object identification by touch. They report a deficit in finger differentiation, although they do not say whether this was only immediately after the operation, or whether it persisted. Of special interest is their observation that the deficit was more evident when the left hand was touched than the right, which agrees with our findings. They found a transient impairment of short-term verbal memory, no impairment of visual memory, and an impairment of memory of the patient's own actions ("autopragmatic amnesia") which was evident six months after operation.

The deficient ability of our patient WF (case 1), in the short-term acquisition of new information (repeated digit and spatial sequences) implicates the corpus callosum for this function. Unlike the patient of Dimond et al. (1977), her exceptional verbal abilities have enabled coping strategies that minimise her deficits outside a laboratory.

Risse et al. (1978) report studies of five patients who had undergone commissurotomy for the relief of intractable seizures, but in whom the anterior commissure had been spared. Tests of interhemispheric transfer indicated complete visual transfer in four out of five of their patients. The one not showing transfer had suffered serious trauma in the left temporal region at a very early age, which may have prevented normal functional connections between the left and right temporal lobes. Their tests suggest that the anterior commissure may be limited in its transfer to nonverbal information. The lack of transfer of tactile information they observe is consistent with our knowledge of somatosensory processing which is not believed to involve the projection field of the anterior commissure. It is also consistent with our own findings, reported above, of a deficit in finger differentiation and localisation of touch since, on their evidence, we should not expect this to be mediated by the intact anterior commissures in our patients. Their evidence for transfer of visual information is at variance with the report by Dimond et al. (1977) of a deficit in transfer of visuospatial information. However, it is not known whether the anterior commissure is capable of developing multimodal interhemispheric transfer in the absence of an acute neuropathological stimulus.

Our long-term studies show that satisfactory results are in general sustained. Two patients have been free from seizures for more than five years; the third does suffer from seizures, but these antedate his operation, and can reasonably be attributed to the underlying tuberose sclerosis.

Our patients do exhibit significant deficits in tests designed to demonstrate interhemispheric transfer of tactile information. Visual transfer, as demonstrated by the chimeric face test, is largely intact. This is of much theoretical interest, since it supports the concept of localisation within the corpus callosum (Jeeves, 1978). But the patients do not appear to suffer much, if any, inconvenience from this subtle incapacity. Admittedly, only one patient is sufficiently articulate and intelligent to complain of such difficulties, but her failure to do so is encouraging. Nor does she complain of any marked impairment of recent memory, as do the patients with partial but more extensive commissurotomies reported by Zaidel and Sperry (1974). Perhaps their more severe mnestic defects reflect the additional section of the callosal genu, the anterior commissure and the hippocampal commissure. Certainly, there is increasing evidence for functional localisation within the commissural system (Doty and Overman, 1977).

\section{References}

Bosch, A., Raehn, T., and Backlund, E. O. (1977). Treatment of colloid cysts of the third ventricle by stereotactic aspiration. Surgical Neurology, 9, 15-18.

Corkin, S. (1965). Tactually-guided maze learning in man: effects of unilateral cortical excisions and bilateral hippocampal lesions. Neuropsychologia, 3, 339-351.

Dennis, M. (1976). Impaired sensory and motor differentiation with corpus callosum agenesis: a lack of callosal inhibition during ontogeny? Neuropsychologia, 14, 455-469.

Dimond, S. J., Scammell, R. E., Brouwers, E. Y. M., and Weeks, R. (1977). Functions of the centre section (trunk) of the corpus callosum in man. Brain, 100, 543-562.

Doty, R. W., and Overman, W. H. (1977). Mnemonic role of forebrain commissures in macaques. In Lateralization of the Nervous System, pp. 75-88. Edited by S. Harnad, R. W. Doty, L. Goldstein, J. Jaynes, and G. Krauthamer. Academic Press: London.

Gazzaniga, M. A. (1970). The Bisected Brain. AppletonCentury-Croft: New York.

Gordon, H. W., Bogen, J. E., and Sperry, R. W. (1971). Absence of deconnexion syndrome in two 
patients with partial section of the neocommissures. Brain, 94, 327-336.

Greenwood, J. (1949). Paraphysical cysts of the third ventricle. Journal of Neurosurgery, 6, 153.

Iizuka, J. (1971). Zerebraldiagnostik im Kindes alter mittels Stereoenzephaloskopie. Zeitschrift für Kinderchirurgie, 10, 2-13.

Jeeves, M. A. (1965). Psychological studies of three cases of congenital agenesis of the corpus callosum. In Functions of the Corpus Callosum, pp. 77-94. Edited by E. G. Ettlinger. Churchill: London.

Jeeves, M. A. (1978). Some limits to interhemispheric integration in cases of callosal agenesis and partial commissurotomy. In The Structure and Function of the Cerebral Commissures. Edited by M. van Hof, I. Steele-Russell, and G. Berlucchi. Macmillan and Plenum: London and New York.

Kinsbourne, M., and Warrington, E. K. (1962). A study of finger agnosia. Brain, 85, 47-66.

Levy, J., Trevarthen, C., and Sperry, R. W. (1972). Perception of bilateral chimeric figures following hemisphere deconnexion. Brain, 95, 61-78.

Long, D. M., and Chou, S. N. (1973). Transcallosal removal of craniopharyngiomas within the third ventricle. Journal of Neurosurgery, 39, 563-567.

McKissock, W. (1951). The surgical treatment of colloid cyst of the third ventricle. Brain, 74, 1-9.

McKissock, W. (1965). Colloid cysts of the third ventricle. Journal of Neurology, Neurosurgery, and Psychiatry, 28, 461.

Milner, B. (1971). Interhemispheric differences and psychological processes. British Medical Bulletin, 27, 272-277.

Reynolds, D. M., and Jeeves, M. A. (1977). Further studies of tactile perception and motor co-ordination in agenesis of the corpus callosum. Cortex, 13, 257-272.

Risse, G. L., Le Doux, J., Springer, S. P., Wilson, D. H., and Gazzaniga, M. S. (1978). The anterior commissure in man: functional variation in a multisensory system. Neuropsychologia, 16, 23-31.

Russell, D. S., and Rubinstein, L. J. (1977). Pathology of Tumours of the Nervous System. Fourth edition. Edward Arnold: London.

Sperry, R. W. (1970). Perception in the absence of neocortical commissures. In Perception and its Disorders: Research Publications of the Association for Research in Nervous and Mental Diseases, 48, 123-128. Williams and Wilkins: Baltimore.

Zaidel, D., and Sperry, R. W. (1974). Memory impairment after commissurotomy in man. Brain, 97, 263272. 